\title{
CONTRIBUIÇÃO PARA A RENOVAÇÃO DAS ABORDAGENS PEDAGÓGICAS NO PROCESSO DE FORMAÇÃO DE ENFERMEIROS
}

[Contribution for the renovation of the pedagogical approach during the nurses' graduation process]

\author{
Cesar Cavalcanti da Silva* \\ Ana Tereza Medeiros Cavalcanti da Silva** \\ Casandra Genoveva R. M. Ponce de Leon*** \\ Maria Benegelânia Pinto****
}

RESUMO: O artigo sugere a renovação das abordagens pedagógicas no processo de formação de enfermeiros e aponta a abordagem por Competências como concepção pedagógica capaz de compatibilizar os aspectos técnicos e políticos nos processos de formação profissional.

PALAVRAS-CHAVE: Educação Baseada em Competências, Educação, Educação em Enfermagem.

\section{INTRODUÇÃO}

A Resolução CNE/CES N. ${ }^{\circ} 3$, de 07 de novembro de 2001 que instituiu as Diretrizes Curriculares dos Cursos de Graduação em Enfermagem coloca em seu artigo $9^{\circ}$ que os cursos de graduação em Enfermagem devem ter um Projeto Pedagógico - PP, construído coletivamente, centrado no aluno como sujeito da aprendizagem e apoiado no professor como facilitador e mediador do processo ensino-aprendizagem. Esse Projeto Pedagógico deverá ainda apoiar uma formação integral e adequada do estudante através da articulação entre o ensino, a pesquisa e a extensão/assistência (BRASIL, 2001).

\footnotetext{
*Enfermeiro, Doutor em Enfermagem, Universidade Federal da Paraíba. ${ }^{* *}$ Enfermeira, Doutora em Enfermagem, Universidade Federal da Paraíba.

***Enfermeira, Mestranda em Enfermagem, Universidade Federal da Paraíba.

${ }^{\star \star \star \star}$ Enfermeira, Mestranda em Enfermagem, Universidade Federal da
}

Quanto aos métodos de ensino ou estratégias pedagógicas, a citada Resolução informa em seu artigo 14, que a estrutura dos cursos de graduação em Enfermagem deverá assegurar a implementação de uma metodologia no processo ensinar-aprender que estimule $o$ aluno a refletir sobre a realidade social e aprenda a aprender (BRASIL, 2001).

Todavia, nem todas as estratégias pedagógicas utilizadas no processo de formação de enfermeiros, asseguram ou promovem uma formação profissional com as características propostas pela referida legislação. Na prática educativa da abordagem tradicional, por exemplo, não há estímulo para a reflexão e a realidade social dificilmente é tomada como substrato do processo ensino-aprendizagem.

Para Zabala (1998), a abordagem pedagógica tradicional condicionou os processos educativos ao longo do último século e, contemporaneamente, ainda é hegemônica nos processos educativos em geral e particularmente na prática educativa para formação de enfermeiros, conforme estudo de Silva; Egry (2003).

Dado que o dispositivo legal apenas indica o que se espera da estratégia pedagógica, é urgente a necessidade de disseminação dos avanços registrados nessa área, particularmente no âmbito da prática educativa, tendo em vista os requerimentos das políticas de inclusão social no âmbito da formação de enfermeiros.

A reflexão sobre as estratégias pedagógicas 
utilizadas nas práticas educativas para formação de enfermeiros, em conformidade com as Diretrizes Curriculares Nacionais tem importância estratégica nesse momento histórico, em razão das necessidades decorrentes do Sistema Único de Saúde - SUS, na área de recursos humanos e a conseqüente mudança de perfis profissionais para atender seus princípios norteadores, tanto doutrinários como organizativos.

Fazer avançar os processos de formação, de modo a que eles sejam compatíveis com os requerimentos dos processos de mudança das ciências da saúde e em particular, dos movimentos políticos de inclusão social, é o que se reclama no presente (MANDU; ALMEIDA, 1999).

No âmbito da formação de enfermeiros, um dos grandes desafios a ser transposto para a renovação das abordagens pedagógicas que sustentam as práticas educativas é o de compatibilizar os aspectos técnicos e políticos nos processos de formação profissional, e veiculá-los através de uma abordagem pedagógica que alimente as práticas educativas para além das necessidades técnicas e se mantenha ajustada aos movimentos de inclusão social.

Partimos do pressuposto que a indicação da abordagem por Competências no Projeto Pedagógico dos cursos de graduação para a formação de enfermeiros, é capaz de promover o alcance das características apontadas pela legislação em vigor.

\section{A ABORDAGEM POR COMPETÊNCIAS NO CONTEXTO DA FORMAÇÃO TÉCNICO- POLÍTICA DE ENFERMEIROS}

Dentre todos os problemas que o Sistema Único de Saúde vem enfrentando desde o seu aparecimento legal na década de 90, ocupa lugar de destaque a formação de recursos humanos incompatível com seus requerimentos operacionais.

Na atualidade, a formação de enfermeiros, precisa acompanhar as transformações em curso no setor saúde, quer seja no plano macro das políticas sociais, quer seja nos micro espaços institucionais que interferem no processo saúde-doença, considerando, sobretudo, os pilares teóricos de sustentação do SUS e o coletivo, como objeto de intervenção das práticas de saúde.

O perfil profissional forjado pelo paradigma educacional vigente não tem acompanhado as transformações ocorridas no setor saúde. Formados a partir de práticas educativas tradicionais, em descompasso com os requerimentos da nova formulação política e organizacional dos serviços de saúde, esses profissionais dificilmente assumirão em sua prática os pilares teóricos de sustentação do SUS, não contribuindo, portanto, para sua efetivação.

Antunes et al. (1999), referem que o uso prolongado e dominante da opção pedagógica da abordagem tradicional favorece o surgimento de distorções nos processos de formação, que se manifestam no âmbito individual, através da passividade, a falta de atitude crítica, a relação dogmática com as fontes de informação, a valorização isolada do saber intelectual e o desinteresse para transformar a realidade. No âmbito coletivo, verifica-se a ocorrência de grupos passivos e acríticos que adotam, indiscriminadamente, modelos e padrões de outras regiões, manipuláveis por comunicação de massa ou reprodutores de padrões historicamente estabelecidos e desvinculados do contexto social de sua realidade.

Como alternativa às abordagens pedagógicas normativas e suas práticas educativas clássicas, propomos a abordagem por Competências, estudada por Phillipe Perrenoud e já bastante difundida em vários países da Europa, especialmente no âmbito do ensino fundamental.

A abordagem por Competências pode representar um passo adiante, rumo à superação das abordagens tradicionais, por sua compatibilidade com os desejos e necessidades de renovação da escola; por individualizar e diversificar os percursos de formação; por se direcionar para uma avaliação formativa e não normativa; por desenvolver o trabalho em equipe; por colocar os discentes no centro da ação pedagógica; por recorrer a métodos ativos de ensino; por desenvolver a competência e a transferência de conhecimentos trabalhando a partir de situações-problema (PERRENOUD, 1999).

A palavra Competência não tem uma definição clara e partilhada. Ao contrário do que 
indica o senso comum, não é a implementação racional pura e simples de Conhecimentos e, embora haja uma relação de complementaridade entre elas, verificam-se diferenças fundamentais.

A diferença entre conhecimentos e competências acarreta para a prática educativa docente a ocorrência de dois tipos de ações pedagógicas: as que optam apenas pela ministração de conhecimentos, sem se preocupar com sua mobilização para construir competências; e aquelas que limitam o repasse de conhecimentos para exercitar sua mobilização em situaçõesproblema (PERRENOUD, 1999).

Situações-problema são contextos, ao mesmo tempo, mobilizadores e orientadores dos processos de ensino para aprendizagens específicas. As práticas educativas baseadas neste artifício didático não implicam apenas em levar o estudante para uma situação qualquer e fazê-lo identificar e resolver problemas. Uma situação deve ser organizada em torno da superação de um "obstáculo" que leve o aluno a investir em conhecimentos anteriores, de modo a que isso o conduza à elaboração de novas idéias (PERRENOUD, 1999).

No âmbito da construção das competências, vale salientar que elas são aprendidas, não sendo, portanto, virtualidades humanas. Construir competências, segundo este autor, implica encontrar, identificar e mobilizar recursos cognitivos que lhes darão suporte. A mobilização dos recursos cognitivos se faz em tempo real, através de esquemas mentais, e a serviço de uma ação eficaz, numa situação específica. Dessa forma, não é possível descrever a construção de uma competência sem que situações-problema, recursos cognitivos e esquemas mentais sejam evocados. Destes três componentes, o mais difícil de objetivar é o esquema mental, pois está no âmbito do pensamento e não pode ser observado. Somente a partir das práticas e dos propósitos dos sujeitos é possível inferir os esquemas (PERRENOUD, 1999).

Não existe, portanto, a menor possibilidade de construir esquemas mentais por simples interiorização de conhecimentos e, tampouco, de promover seu implante em alunos, uma vez que não podem ser programados por intervenção externa. Os esquemas de mobilização de recursos cognitivos são construídos individualmente, por meio de experiências renovadas em situações práticas, e serão tanto mais eficazes quanto mais reflexivas e críticas forem as posturas dos sujeitos (PERRENOUD, 1999).

Para passar de uma lógica de ensino baseada apenas no repasse de conhecimentos para outra, ancorada no postulado de que se constroem competências exercitando-se em situações complexas, a formação de profissionais de saúde no interior das universidades terá que experimentar várias mudanças em seu processo pedagógico.

A principal mudança deverá ocorrer nas atividades docentes, e o primeiro passo nesta direção é identificar e trabalhar a relação entre as abordagens pedagógicas e as práticas educativas dela decorrentes.

\section{SUGESTÃO PARA COMPOSIÇÃO DE UM PROJETO PEDAGÓGICO PARA FORMAÇÃO DE ENFERMEIROS A PARTIR DAABORDAGEM POR COMPETÊNCIAS}

As modificações ocorridas nas políticas de educação e de saúde no país determinaram, ao longo dos últimos anos, um gradativo relaxamento, por parte dos formadores, nas questões pedagógicas e, especificamente, no suporte político necessário à compreensão dos conteúdos e sua aplicação. Esse relativo esvaziamento nos processos de formação atingiu fortemente as profissões da área da saúde e desenhou a necessidade de uma recomposição políticopedagógica no setor, já viabilizada de forma legal.

Apresenta-se a seguir, uma proposta de Projeto Pedagógico para a formação de enfermeiros cujo desenho contém uma série de capacidades a serem trabalhadas por estes profissionais mas, sobretudo, o estabelecimento das bases para seu posicionamento político diante dos fatos.

\section{PROJETO POLÍTICO PEDAGÓGICO}

\section{OBJETIVOS}

- Desenvolver nos enfermeiros uma postura crítica e questionadora do contexto sócio-político no qual está inserido, a partir da construção de competências específicas e de referência que potencialize a integração ensino-serviço e 
compatibilize os requerimentos dos movimentos políticos de inclusão social com os processos de formação profissional.

- Articular os conhecimentos adquiridos na Universidade com a prática social, visando à construção de competências que possibilitem uma postura reflexiva, questionadora e crítica em relação à política de saúde vigente no país; e repercutam sobre as políticas de saúde regionais e locais.

\section{ESPECÍFICOS}

- Mobilizar formalmente docentes e discentes das Universidades, no sentido do desenvolvimento da integração ensino-serviço e articulação teoriaprática.

- Identificar as características locais do sistema de saúde e acionar estratégias de intervenção, implantando e/ou atuando em programas sociais de saúde e educação.

- Promover atividades de educação continuada, visando ao estabelecimento de um feedback entre os conhecimentos gerados na Universidade e na própria comunidade.

- Realizar pesquisas em todos os níveis de prestação de serviço, enfatizando aquelas referentes aos cuidados primários e que subsidiem futuras propostas de intervenção.

\section{PREMISSAS NA DEFINIÇÃO DAS PROPOSTAS DE TRABALHO}

Visando a respaldar os objetivos transformadores das ações pedagógicas dos professores, o presente Projeto Pedagógico orientará suas ações com base nas seguintes premissas:

- Estímulo à capacidade de reflexão crítica pois é a crítica que permite o desvendamento dos discursos e dos conflitos, a sutil vontade do poder das ideologias, o antagonismo dos interesses políticos e econômicos, a pretensa neutralidade da ciência e da técnica, os totalitarismos e micro poderes cotidianos.

- Estímulo ao pensamento simultâneo do local e do global - dado que o processo de globalização em curso exige o desenvolvimento da capacidade de refletir, relacionar e agir, tanto nos planos local e regional, quanto no nacional e mundial.

- Estímulo ao olhar pluridimensional - pois as explicações unidimensionais da realidade são pouco confiáveis, e a constituição do real é sempre mais plural que singular, fazendo com que sua interpretação exija a observação das múltiplas dimensões que o condicionam.

- Estímulo à integração teoria-prática - pois o diálogo criativo entre a teoria e a prática ganha importância na mesma proporção em que perdem a força e o sentido, quando são tratadas como realidades isoladas.

\section{COMPETÊNCIAS E HABILIDADES}

Os avanços esperados no campo da participação social, apontam para uma renovação constante das competências e habilidades profissionais. A formação de enfermeiros voltada apenas para a aquisição de conhecimentos já não responde às necessidades dos programas de inclusão social. Assim sendo, o presente Projeto Pedagógico deverá proporcionar ao egresso:

- A capacidade para utilizar os conhecimentos como aliados na construção das Competências;

- O desenvolvimento de sua capacidade de reflexão crítica, através do olhar multidimensional sobre a realidade;

- A habilidade para questionar e posicionarse frente aos problemas que emergem das políticas educação e de saúde, intervindo, tanto quanto seja possível, nessa realidade, dentro de sua esfera de ação.

\section{ABORDAGEM PEDAGÓGICA E PRÁTICA EDUCATIVA}

Os processos de ensino visam à formação de Competências específicas para o enfrentamento das questões ligadas ao processo saúde-doença das populações alvo. Estes processos são tomados a partir da articulação das dimensões individual e coletiva na abordagem por Competências, que deve subsidiar os processo de ensino e de avaliação, ou práticas educativas.

\section{PERFIL PROFISSIONAL}

O futuro enfermeiro estará apto a:

- Criticar as formas de inserção da 
Universidade nas comunidades, no sentido de ampliar essa participação;

- Refletir sobre sua interseção e responsabilidades, no âmbito da equipe de saúde e construção do Sistema Único de Saúde;

- Questionar e posicionar-se frente às políticas de saúde, local, regional e nacional.

Para isso, o aluno deve:

- Contar com a ajuda do professor, através de práticas educativas baseadas na abordagem por Competências, como suporte para os processos de ensino;

- Ter capacidade de ampliar seus conhecimentos de forma independente e utilizálos na construção de Competências de referência e específicas.

\section{CONSIDERAÇÕES FINAIS}

No âmbito das práticas educativas e sua relação com as estratégias pedagógicas, tendo em vista a formação de enfermeiros em atenção aos requerimentos das políticas de inclusão social, urge superar os atuais processos de ensino e de avaliação, estruturados sob modelos pedagógicos tradicionais e, portanto, desatualizados.

A indicação da estratégia pedagógica de formação de Competências para compor o Projeto Pedagógico dos processos de formação de enfermeiros, coincide com a tese de que, para práticas educativas em saúde com horizonte de transformação, é preciso assumir processos pedagógicos baseados na formação de Competências, com objetivos transformadores.

ABSTRACT: The article suggests the renovation of the pedagogical approaches in the nurses graduation process, and points the competency approach as a pedagogical conception capable to make compatible the technician and politicians aspects in the processes of professional formation.

KEY WORDS: Competency-Based Education, Education, Nursing Education.

\section{REFERÊNCIAS}

ANTUNES, M. J. M.; SHIGUENO, L. Y. O.; MENEGHIN, P. Métodos pedagógicos que influenciaram o planejamento das ações educativas dos enfermeiros: revisão bibliográfica. Rev Esc Enf USP, São Paulo, v.33, n.2, p.165 74. 1999.

BRASIL. Conselho Nacional de Educação. Câmara de Educação Superior. Resolução CNE/ CES 03 de 07 de novembro de 2001. Diário Oficial da União, Brasília, 9 de Novembro de 2001. Seção 1, p.37

MANDU, E.N.T.; ALMEIDA, M.C.P. Necessidades em saúde: questões importantes para o trabalho da enfermagem. Rev. Bras. Enferm., Brasília, v.52, n. 1, p. 54-66. 1999.

PERRENOUD, P. Construir as competências desde a escola. Porto Alegre: Artes Médicas, 1999.

SILVA, C. C.; EGRY, E. Y. Competências na prática educativa para constituição da força de trabalho em saúde: um desafio aos educadores. [tese] São Paulo (SP): Escola de Enfermagem da USP; 2003.

ZABALA, A. A prática educativa: como ensinar. Porto Alegre: ArtMed, 1998.
ENDEREÇO DOS AUTORES Av. Umbuzeiro, n. ${ }^{\circ} 209$ Manaíra 58038-180 João Pessoa/PB cesar@jpa.neoline.com.br 